\title{
Prevalence of overweight and obesity in British children: cohort study
}

\author{
John J Reilly, Ahmad R Dorosty, Pauline M Emmett
} are necessary so that the need for preventive measures can be assessed, secular trends monitored, and high risk population groups identified. ${ }^{1}$ The aim of this study was therefore to provide current estimates of the prevalence of obesity among British children.

\section{Subjects, methods, and results}

Subjects consisted of a birth cohort randomly selected from a larger geographically defined total population cohort born in the Bristol-Avon area in 1991-2. The cohort has been described elsewhere ${ }^{2}$ and is broadly representative of children in the United Kingdom. Height (to $0.1 \mathrm{~cm}$, measured with a Leicester height meter) and weight in underwear (to $0.1 \mathrm{~kg}$, measured with Seca scales) were measured in children at 24, 49, and 61 months of age.

There is a consensus that childhood obesity should be defined by using the body mass index (weight $(\mathrm{kg})$ / (height $\left.(\mathrm{m}))^{2}\right),{ }^{13}$ a simple proxy for body fatness that is interpreted relative to population reference data. ${ }^{134}$ The following recommended cut offs ${ }^{3}$ were applied to United Kingdom reference data ${ }^{4}$ : a standard deviation score $>1.04$ for body mass index (above the 85 th centile) was defined as overweight, and a standard deviation score $>1.64$ (above the 95th centile) was defined as obese. These definitions set the percentage of children expected to be overweight (15\%) and obese $(5 \%)$ and "fix" these expected frequencies at the time of the United Kingdom 1990 reference data. ${ }^{14}$ The cut off used to define obesity is not arbitrary: children with a body mass index above the 95th centile are likely to be excessively fat, ${ }^{35}$ and obesity defined in this way has a strong likelihood of persisting to adulthood and is associated with several adverse health outcomes. ${ }^{3}$

The table shows data on the prevalence of overweight and obesity. Differences in prevalence between boys and girls were not significant. The prevalence of obesity significantly exceeded expected frequencies at 49 and 61 months ( $\chi^{2}$ goodness of fit tests).

\section{Comment}

This study showed an excess of overweight and obesity in children before the age of school entry. These data are consistent with evidence of an epidemic of adult obesity and support the view that efforts to prevent obesity should begin in early childhood.

Updating growth charts to allow for secular trends would obscure such trends and so the prevalence of obesity should be expressed relative to contemporary reference data at a fixed point in time. ${ }^{1}$ We used way. ${ }^{4}$ Given the rise in the prevalence of obesity and overweight since these were compiled, monitoring of secular trends in childhood obesity is indicated. Trends in prevalence might be obscured, however, if only body mass index is monitored because changes in this index
Estimates of the prevalence of obesity among children contemporary United Kingdom reference data in this cannot be readily separated into changes in fat mass and fat free mass (body mass index is a proxy for both).$^{3-5}$ Secular trends would be more easily identified by monitoring other variables such as skinfold thickness or body fat percentage. ${ }^{5}$

The definitions of overweight and obesity used in this study are based on a simple proxy for body fatness-body mass index-rather than direct measurements of body fatness. As a proxy, body mass index is highly specific for obesity ${ }^{35}$ (it identifies few non-obese children as obese) but insensitive ${ }^{5}$ (it fails to identify relatively large numbers of obese children). Since our definition of obesity is conservative, the true prevalence of childhood obesity in the United Kingdom will be higher than the estimates generated in this study.

We thank Dr Jan Love of the Robertson Centre for Biostatistics for statistical advice and are grateful to all the parents and children for their cooperation. The ALSPAC (Avon longitudinal study of pregnancy and childhood) study team consists of interviewers, technicians, clerical workers, scientists, volunteers, and managers: we are grateful for their help and advice.

Contributors: JJR initiated core ideas; supervised ARD; participated in data analysis, data interpretation, and writing of the paper; and is guarantor. ARD discussed core ideas, carried out data analysis, and participated in data interpretation and writing of the paper. PME discussed core ideas; was involved in training staff and quality control of data collected; and participated in data analysis, interpretation, and writing of the paper.

Funding: The ALSPAC study was supported by various groups, including the Wellcome Trust, Department of Health, and Ministry of Agriculture, Fisheries and Food. ARD was sponsored by the Iranian Ministry of Health and Medical Education. Competing interests: None declared.

1 Prentice AM. Body mass index standards for children. BMJ 1998;317:1401-2.

2 ALSPAC. Children of the nineties. http://alspac2.ich.bris.ac.uk/ alspacext/Default.html (accessed 30 Sep 1998).

3 Barlow SE, Dietz WH. Obesity evaluation and treatment: expert committee recommendations. Pediatrics 1998;102:e29.

Cole TJ, Freeman JV, Preece MA. Body mass index reference curves for the UK, 1990. Arch Dis Child 1995;73:25-9.

5 Reilly JJ, Savage SAH, Ruxton CHS, Kirk TR. Assessment of obesity in a community sample of prepubertal children. Int J Obes 1999;23:217-9. (Accepted 29 July)

Prevalence of obesity and overweight in children at ages 24,49 , and 61 months

\begin{tabular}{|c|c|c|c|}
\hline & \multicolumn{3}{|c|}{ Age (months) } \\
\hline & 24 & 49 & 61 \\
\hline \multicolumn{4}{|l|}{ Both sexes: } \\
\hline Total No & 1031 & 1013 & 972 \\
\hline No (\%) overweight & $163(15.8)^{\star}$ & $206(20.3)^{\star *}$ & $182(18.7)^{\star * *}$ \\
\hline No (\%) obese & $62(6.0)$ & $77(7.6)^{\star *}$ & $70(7.2)^{\star \star}$ \\
\hline \multicolumn{4}{|l|}{ Boys: } \\
\hline Total No & 562 & 562 & 532 \\
\hline No (\%) overweight & 78 (13.9) & $112(19.9)^{* *}$ & $97(18.2)^{\star *}$ \\
\hline No (\%) obese & $33(5.9)$ & $42(7.5)^{\star \star}$ & $43(8.1)^{\star \star}$ \\
\hline \multicolumn{4}{|l|}{ Girls: } \\
\hline Total No & 469 & 451 & 440 \\
\hline No (\%) overweight & $85(18.1)$ & $94(20.8)^{\star \star}$ & $85(19.3)^{\star *}$ \\
\hline No (\%) obese & $29(6.2)$ & $35(7.8)^{\star \star}$ & $27(6.1)^{\star \star}$ \\
\hline
\end{tabular}

Significantly different from expected frequency of $15 \%$ (body mass index above 85 th centile) or $5 \%$ (body mass index above 95th centile) at ${ }^{*} \mathrm{P}<0.05,{ }^{*} \mathrm{P}<0.001$.

\section{University of \\ Glasgow \\ Department of \\ Human Nutrition, \\ Yorkhill Hospitals, \\ John J Reilly \\ senior lecturer \\ Ahmad R Dorosty \\ research student \\ ALSPAC Study \\ Team, Unit of \\ Paediatric and \\ Perinatal \\ Epidemiology, \\ Institute of Child \\ Health, University \\ BS8 1TH \\ Pauline M Emmett \\ nutritionist \\ Correspondence to: Dr Reilly \\ jir2y@clinmed. \\ gla.ac.uk}

BMJ 1999;319:1039 